\title{
Administration of a VEGFR-2-specific MRI contrast agent to assess orthodontic tooth movement
}

\section{A pilot study}

\author{
Agnes Schröder ${ }^{1}$ Lisa Seyler ${ }^{2}$ Elisabeth Hofmann ${ }^{3} \cdot$ Lina Gölz ${ }^{4}$ Jonathan Jantsch ${ }^{5}$ Peter Proff' • \\ Tobias Bäuerle ${ }^{2}$. Christian Kirschneck ${ }^{1}$
}

Received: 30 April 2020 / Accepted: 6 May 2021 / Published online: 16 July 2021

(c) The Author(s) 2021

\begin{abstract}
Purpose It is thought that orthodontic forces initially reduce periodontal blood flow during orthodontic tooth movement (OTM) via tissue compression with cells responding to concomitant oxygen deprivation with expression of vascular endothelial growth factor (VEGF) triggering angiogenesis via binding to its receptor VEGFR-2. To test this hypothesis, we performed a pilot study to establish a protocol for molecular magnetic resonance imaging (MRI) of rat jaws administering a VEGFR-2-specific contrast agent.

Methods Mesial OTM of a first upper left rat molar was initiated in one male Fischer 344 rat 4 days prior to MRI by insertion of an elastic band between the first and second upper molars with the contralateral side left untreated (internal control). T1-weighted MRI sequences including dynamic contrast-enhanced MRI (DCE-MRI) were recorded before and after administration of a molecular VEGFR-2 MRI marker with a 7T MRI dedicated for small animal use.

Results After injection of anti-VEGFR2-albumin-gadolinium-DTPA, volume enhancement on T1-weighted images was increased at the OTM side distally of the moved first upper molar (M1) compared to the control side, whereas the T1 relaxation time was reduced on the OTM side. DCE-MRI resulted in an increased area under the curve (AUC), whereas time-to-peak (TTP) and washout rate were reduced during OTM distally of the moved M1 compared to the contralateral side.

Conclusions OTM resulted in uptake of the VEGFR-2-specific MRI contrast agent in tension areas of the periodontal ligament. The imaging protocol presented here is useful for the assessment of VEGFR-2 expression in tension areas of the periodontal ligament in vivo.
\end{abstract}

Keywords Periodontal ligament · Vascular endothelial growth factor receptor-2 $\cdot$ Molecular magnetic resonance imaging $\cdot$ Hypoxia $\cdot$ Animal models

Christian Kirschneck

christian.kirschneck@ukr.de

1 Department of Orthodontics, University Hospital Regensburg, 93053 Regensburg, Germany

2 PIPE (Preclinical Imaging Platform Erlangen) and Department of Radiology, University of Erlangen-Nuremberg, 91054 Erlangen, Germany

Private Orthodontic Practise, 44649 Herne, Germany

4 Department of Orthodontics, University of Erlangen-Nuremberg, 91054 Erlangen, Germany

5 Institute of Clinical Microbiology and Hygiene, University Hospital Regensburg, 93053 Regensburg, Germany 


\section{Verabreichung eines VEGFR-2-spezifischen MRT-Kontrastmittels zur Beurteilung der kieferorthopädischen Zahnbewegung}

Eine Pilotstudie

\section{Zusammenfassung}

Zielsetzung Es wird angenommen, dass kieferorthopädische Kräfte initial den parodontalen Blutfluss während der kieferorthopädischen Zahnbewegung (OTM) durch Gewebekompression reduzieren, wobei die beteiligten Zellen auf einen begleitenden Sauerstoffmangel mit einer Expression des vaskulären endothelialen Wachstumsfaktors (VEGF) reagieren, der über die Bindung an seinen Rezeptor VEGFR-2 die Angiogenese induziert. Um diese Hypothese zu untersuchen, führten wir eine Pilotstudie durch, um ein Protokoll für die molekulare Magnetresonanztomographie (MRT) von Rattenkiefern nach Verabreichung eines VEGFR-2-spezifischen Kontrastmittels zu etablieren.

Material und Methoden Bei einer männlichen Fischer-344-Ratte wurde der erste obere Molar (M1) auf der linken Kieferseite 4 Tage vor der MRT durch Einbringen eines elastischen Bandes zwischen dem ersten und zweiten oberen Molaren mesialisiert, wobei die kontralaterale Seite unbehandelt blieb (interne Kontrolle). T1-gewichtete MRT-Sequenzen einschließlich dynamischer kontrastmittelunterstützter MRT (DCE-MRT) wurden vor und nach der Verabreichung eines molekularen VEGFR-2-MRT-Markers mit einem 7-Tesla-MRT für Kleintiere aufgezeichnet.

Ergebnisse Nach Injektion von Anti-VEGFR2-Albumin-Gadolinium-DTPA war die Volumenanhebung auf T1-gewichteten Bildern auf der OTM-Seite distal des bewegten ersten oberen Molaren (M1) im Vergleich zur Kontrollseite erhöht, während die T1-Relaxationszeit auf der OTM-Seite verkürzt war. Die DCE-MRT führte zu einer erhöhten Fläche unter der Kurve (AUC), während die TTP-Zeit bis zum Spitzenwert und die Auswaschungsrate während der OTM distal des bewegten M1 im Vergleich zur kontralateralen Seite reduziert waren.

Schlussfolgerungen Die kieferorthopädische Zahnbewegung führte zur Aufnahme des VEGFR-2-spezifischen MRT-Kontrastmittels in Zugzonen des Parodontalligaments. Das hier vorgestellte Bildgebungsprotokoll hat sich für die In-vivo-Beurteilung der VEGFR-2-Expression in Zugzonen des Parodonts als nützlich erwiesen.

Schlüsselwörter Parodontalligament · Vaskulärer endothelialer Wachstumsfaktor-Rezeptor-2 (VEGFR-2) · Molekulare Magnetresonanztomographie $\cdot$ Hypoxie $\cdot$ Tiermodelle

\section{Introduction}

When orthodontic forces are applied, compression and tension areas develop in the periodontal ligament. This initiates a complex molecular cascade involving multiple molecular and inflammatory mediators $[15,22,30]$, released by mechanically stressed periodontal ligament fibroblasts [4], osteoblasts and cells of the immune system such as macrophages and T cells [29]. Stimulation of mechanosensitive ion channels and receptors in the cell membrane occurs [3]. Cells in the periodontal ligament appear to respond to mechanical stimuli by upregulating cellular mediators such as cyclic AMP, which catalyzes the phosphorylation of mediator proteins $[5,15]$. Depending on these, either cell proliferation or cell differentiation may be stimulated within the cell nucleus. This is controlled by the phosphorylation of transcription factors, such as c-Jun and c-Fos [3]. If inflammatory processes are involved, cyclooxygenase $2(\mathrm{COX}-2)$ can produce prostaglandin E2 (PGE2), which plays an important role in bone resorption [21]. Inflammatory processes continue to stimulate mononuclear phagocytic cells, such as macrophages. These secrete proinflammatory cytokines which stimulate the secretion of prostaglandins [2]. During the application of orthodontic forces, these cytokines appear to stimulate the secretion of the receptor activator of nuclear factor kappa B ligand (RANKL) by osteoblasts and periodontal ligament cells in periodontal tissue $[20,31]$ and osteocytes in the alveolar bone [19, 23]. Recent studies provide evidence that osteocytes are critically involved in OTM via expression of RANKL. RANKL is essential for the differentiation of osteoclast precursor cells into active multinucleated osteoclasts, which are responsible for bone resorption.

However, orthodontic forces not only have cellular effects, but also affect the circulation within the periodontal ligament. Compression of blood vessels, especially in pressure areas during orthodontic force application, is assumed to effect reduced perfusion and thus hypoxia, i.e., a reduced supply of oxygen of the periodontal tissue below physiological levels $[8,18]$. Depending on the oxygen gradient, either the proliferation of different cells is stimulated or, in extreme cases, apoptosis [18]. Hypoxia has a direct influence on the energy balance within the cell via a decrease in glycolytic activity and ATP production. The cell responds to oxygen deprivation by expression of various cellular mediators, such as hypoxia-induced factor-1 (HIF-1), which stimulates angiogenesis and cell proliferation [8]. 
In addition, hypoxia has a special significance for transcriptionally regulated VEGF (vascular endothelial growth factor) expression. Thus, hypoxia via an increase in the HIF- $1 \alpha$ level is the relevant inducer for the gene expression of VEGF under various pathophysiological conditions $[14,16,24]$. VEGF is an important signalling molecule that is effective in both vasculogenesis and angiogenesis. As the name implies, this factor mainly stimulates vascular endothelium, but it also stimulates the migration of monocytes and macrophages. Seven different forms of VEGF are known (A-F and PIGF) [32]. All members of the VEGF family effect a cellular response by binding to a tyrosine kinase, the VEGF receptor (VEGFR), thus, relaying the extracellular signal to the cell interior. The stimulation of VEGF by binding to one of its receptors, VEGFR-2, triggers the proliferation and migration of endothelial cells, as well as the increase of vascular permeability by activation of various signalling pathways (phosphatidylinositol 3'kinase [PI3K]/Akt and Ras/mitogen activated protein kinase $[\mathrm{MAPK}]$ ), thus, effecting increased angiogenesis and in turn improving perfusion and oxygen supply within the periodontal ligament [7].

Despite the supposed effects of orthodontic force application on local microcirculation within the periodontal ligament and concomitant hypoxia-mediated angiogenesis during orthodontic tooth movement (OTM), it is still unclear to what extent local perfusion is actually altered during OTM and how this impacts on associated VEGF-induced angiogenesis within the periodontal ligament. For this reason, we performed a pilot study in the animal model rat using magnetic resonance imaging (MRI) to establish an imaging protocol for administration and detection of a VEGF receptor 2 (VEGFR-2)-specific MRI contrast agent within the periodontal ligament of an orthodontically moved upper rat molar.

\section{Materials and methods}

\section{General information regarding the animal experiment}

One male Fischer 344 rat (Rattus norvegicus Berkenhout, Charles River Laboratories, Sulzfeld, Germany) was included in this pilot study. The rat was 7 weeks old at the beginning of the experiment, which was carried out with the approval of the responsible authorities (Government of Lower Franconia, AZ: 55.2.2532-2-510) and in compliance with the German Animal Protection Act. In order to avoid unnecessary animal suffering, corresponding termination criteria were predefined and animal condition as well as gross body weight monitored daily. The animal was kept in a conventional S1 animal laboratory at the Univer- sity of Erlangen-Nuremberg (Preclinical Experimental Animal Centre PETZ) and had ad libitum access to tap water and to a standard rat diet (V1535, ssniff) with feed pellets. After 4 days of OTM and after the respective mMRI (molecular magnetic resonance imaging) measurements, the rat was euthanized by an i.p. injection of $200 \mathrm{mg}$ Narcoren per kg gross body weight (Merial $\mathrm{GmbH}$, Hallbergmoos, Germany) according to legal guidelines.

\section{Induction of orthodontic tooth movement}

After 7 days of acclimatization, the rat was sedated by intraperitoneal (i.p.) injection of $6 \mathrm{mg}$ xylazine and $90 \mathrm{mg}$ ketamine per kg gross body weight [11] and an orthodontic elastic band (774-200-01, Dentaurum, Ispringen, Germany) was inserted into the approximal space between the first and second upper left molar of the rat according to the method described by Waldo and Rothblatt ([27]; Fig. 2a). The contralateral jaw side was left untreated and served as nonforce internal control [11]. The renewed expansion of the compressed elastic band caused a reciprocal orthodontic force and divergence of the first and second upper left molars and thus an anterior experimental tooth movement of the first upper left molar for 4 days. After insertion, the oral cavity was disinfected with a cotton pellet soaked in chlorhexidine.

\section{Magnetic resonance imaging without/with an VEGFR-2 marker}

Quantitative assessment of local VEGFR-2 expression with and without OTM was carried out by magnetic resonance imaging (MRI) in this study. MRI allows in vivo characterization and measurement of biological processes at the cellular level [28]. The examination by MRI was performed 4 days after insertion of the elastic band, since at this time the cellular tissue response during the induced OTM is reported to be most pronounced [27]. To assess the kinetics of a VEGF receptor 2 (VEGFR-2)-specific contrast agent within the periodontal ligament of the orthodontically moved upper rat molar compared to the contralateral control side, we obtained a corresponding validated molecular MRI marker (anti-VEGFR-2 bound to albumin (Gd-diethylene penta-acetic acid [DTPA])_biotin, Rheal A. Towner, Advanced Magnetic Resonance Center, Oklahoma Medical Research Foundation, and The Oklahoma Center for Neurosciences, The University of Oklahoma Health Sciences Center, Oklahoma City, OK, USA). After 4 days of OTM, the rat was anesthetized with $4 \%$ isoflurane and maintained at $1.5 \%$ isoflurane. The head of the rat was fixed in a rat brain MRT surface coil and scanned on a preclinical 7 T MRI scanner (Fig. 1, ClinScan 70/30, Bruker, Ettlingen, Germany). Respiration was monitored by a pres- 


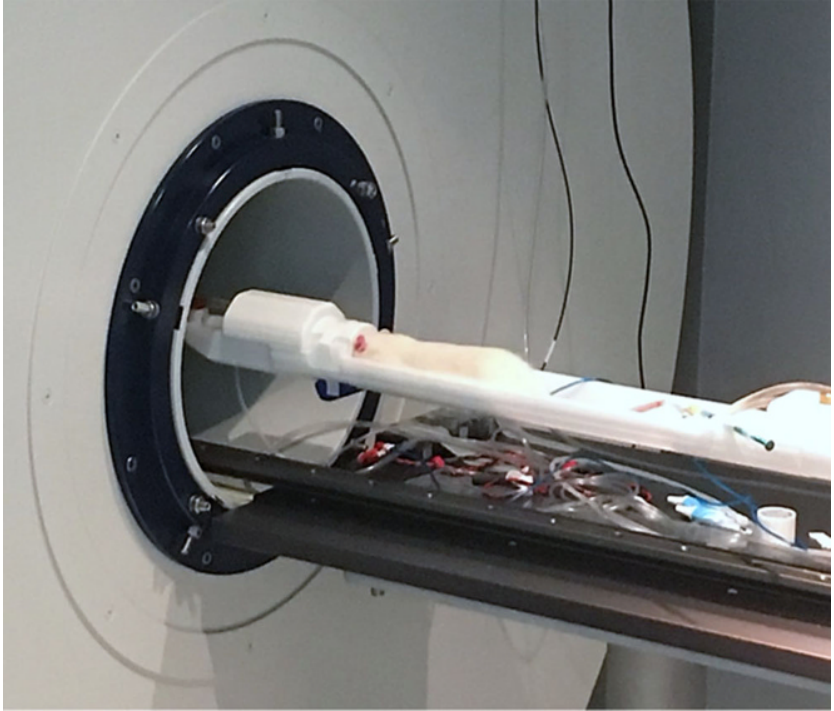

Fig. 1 MRI (magnetic resonance imaging) in the rat using a $7 \mathrm{~T}$ MRI scanner dedicated for small animals

Abb. 1 MRT (Magnetresonanztomographie) einer Ratte mit einem 7-Tesla-MRT-Scanner für Kleintiere

sure sensor and kept constant during the entire imaging procedure. Also the body temperature was kept constant employing a heating bed for the animal. A T1-weighted spin echo sequence (TR: $600 \mathrm{~ms}$, TE: $10 \mathrm{~ms}$, voxel size: $0.078 \times 0.078 \times 0.7 \mathrm{~mm}$, acquisition time: $12: 05 \mathrm{~min})$ pre- ceded the administration of the molecular marker. Dynamic contrast-enhanced MRI (DCE-MRI) was performed using a fast low angle shot (FLASH) sequence with the following parameters: TR: $2.92 \mathrm{~ms}$, TE: $0.88 \mathrm{~ms}$, flip angle: $25^{\circ}$, voxel size: $0.182 \times 0.182 \times 0.7 \mathrm{~mm}$, acquisition time: $12 \mathrm{~min}$ $18 \mathrm{~s}$ and 100 measurements. Then, $200 \mu \mathrm{l}$ of anti-VEGFR-2BSA-Gd-DTPA-biotin was injected intravenously into a tail vein catheter $(24 \mathrm{G})$ after $30 \mathrm{~s}$ and over a time period of $10 \mathrm{~s}$. After running the DCE sequence the above-mentioned T1weighted MRI sequence was repeated and a T1-mapping sequence with the following parameters was scanned: acquisition time: 7:35 min, voxel size: $0.313 \times 0.313 \times 0.6 \mathrm{~mm}$, TR: $40 \mathrm{~ms}$, TE: $1.5 \mathrm{~ms}$, flip angle $1: 5^{\circ}$, flip angle $2: 29^{\circ}[9$, $10,25,26]$

\section{Analysis of MRI datasets and dynamic contrast- enhanced (DCE) MRI}

The periodontal region of the first upper left and right molars within the T1-weighted images was analyzed. For determination of the volume enhancement after administration of anti-VEGFR-2-BSA-Gd-DTPA-biotin, T1-weighted images were segmented using a threshold of 100 for signal intensity. Relaxation times in the selected regions of interest (ROIs) were derived from T1-mapping and DCE-MRI resulted in the semiquantitative parameters area under the curve (AUC), time to peak (TTP) and washout (WO).
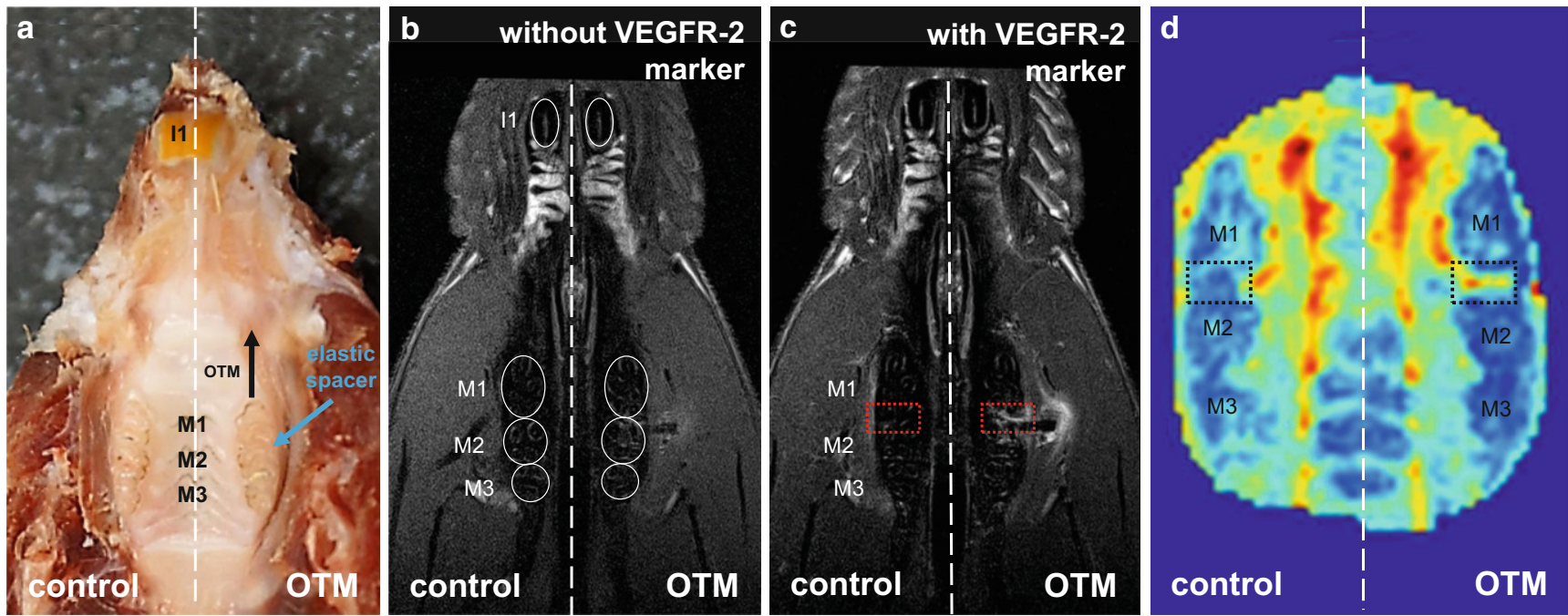

Fig. 2 a Experimental anterior orthodontic tooth movement (OTM) of the first upper left molar (M1) by insertion of an elastic band (774-200-01, Dentaurum, Ispringen, Germany) between the first (M1) and second (M2) upper left molar according to the Waldo/Rothblatt method. b Axial T1MRI section at the root level of the rat molars before i.v. injection of the VEGFR-2 molecular marker. $\mathbf{c}$ Axial T1-MRI plane at the root level of the rat molars after i.v. injection of the VEGFR-2 molecular marker. $\mathbf{d}$ Area under the curve (AUC) mapping of dynamic contrast-enhanced MRI (DCE-MRI). VEGFR vascular endothelial growth factor, OTM left jaw side with orthodontic tooth movement; control untreated right jaw side

Abb. 2 a Experimentelle kieferorthopädische Zahnbewegung (OTM) des ersten oberen linken Molaren (M1) durch Insertion eines elastischen Bandes (774-200-01, Dentaurum, Ispringen, Deutschland) zwischen dem ersten (M1) und zweiten (M2) oberen linken Molaren nach der Waldo/ Rothblatt-Methode. b Axialer T1-MRT-Schnitt auf Wurzelniveau der Molaren der Ratte vor i.v.-Injektion des molekularen Markers VEGFR-2. c Axiale T1-MRT-Ebene auf Wurzelniveau der Molaren der Ratte nach i.v.-Injektion des molekularen Markers VEGFR-2. d AUC(Fläche unter der Kurve)-Kartierung der DCE-MRI. VEGFR „vascular endothelial growth factor“, OTM linke Kieferseite mit kieferorthopädischer Zahnbewegung; Kontrolle unbehandelte rechte Kieferseite 

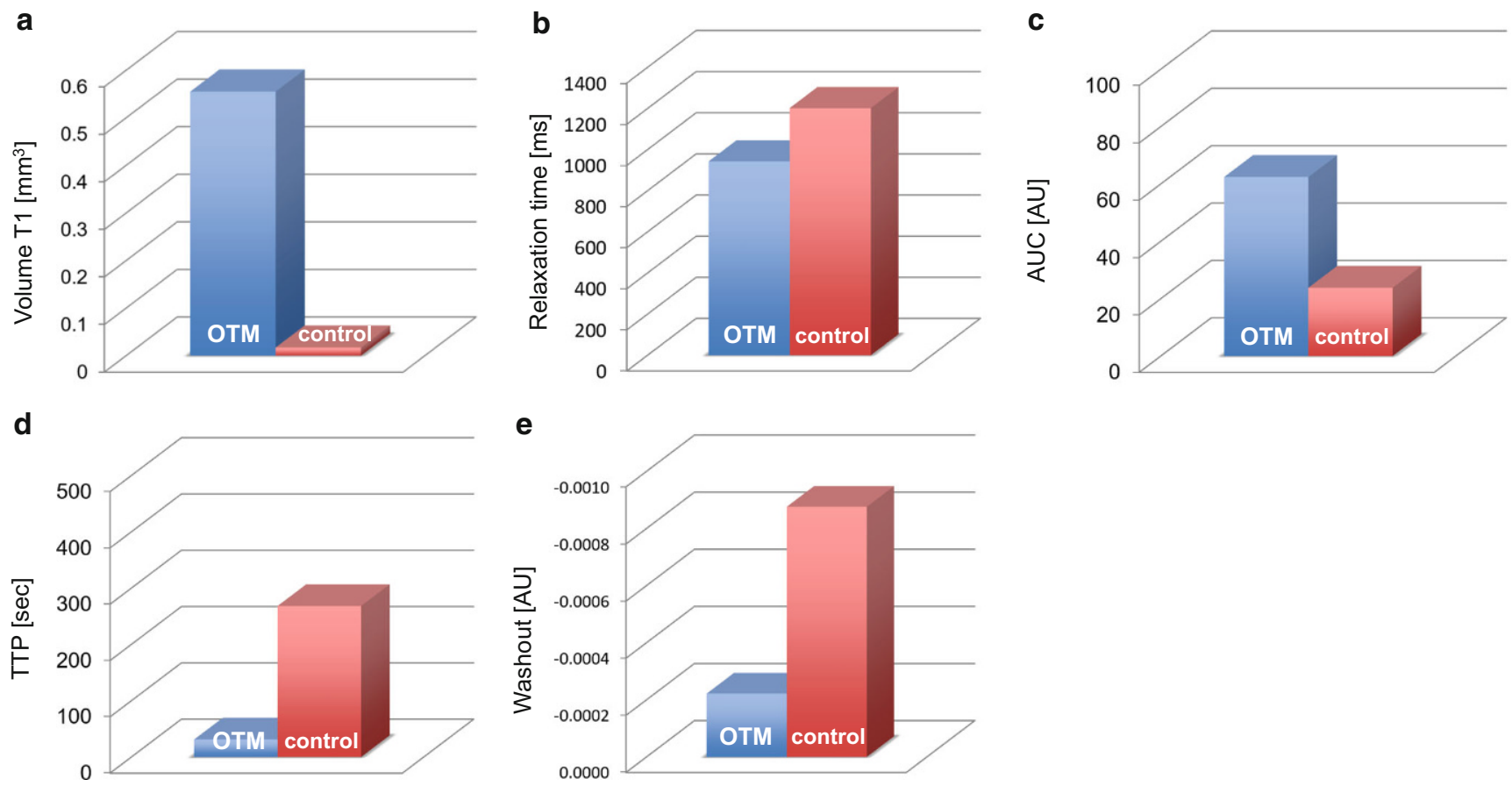

Fig. 3 Results from the MRI analyses after i.v. injection of the VEGFR-2 molecular marker at the left jaw side with orthodontic tooth movement (OTM) and the contralateral right untreated jaw side (control). a mMRI volume T1. b mMRI relaxation time. c Dynamic contrast-enhanced MRI (DCE-MRI) area under the curve (AUC). d Time to peak (TTP). e DCE-MRI washout rate. $A U$ arbitrary units

Abb. 3 Ergebnisse der MRT-Analysen nach i.v.-Injektion des molekularen Markers VEGFR-2 auf der linken Kieferseite mit kieferorthopädischer Zahnbewegung (OTM) und der kontralateralen rechten unbehandelten Kieferseite (Kontrolle). a mMRT-Volumen T1. b mMRI-Relaxationszeit. c DCE-MRT(dynamische kontrastmittelunterstützte MRT)-Bereich unter der Kurve (AUC). d Zeit bis zur Spitze (TTP). e DCE-MRT-Auswaschrate. $A U$ arbiträre Einheiten

\section{Results}

\section{Analysis of a T1-weighted mMRI of the upper jaw during orthodontic tooth movement}

In this pilot study, we first assessed $\mathrm{T} 1$ volume, which represents the enrichment of the molecular marker for VEGFR-2 in the indicated region of interest (ROI) (Fig. 2b,c). Intravenous injection of the molecular marker for VEGFR-2 resulted in an increased $\mathrm{T} 1$ volume in the distal part of the periodontal ligament at the orthodontically moved upper first left molar compared to the contralateral control side (Fig. 2c and 3a). T1 relaxation time was reduced on the OTM side compared to the untreated side (Fig. $3 b$ ).

\section{Analysis of DCE-MRI datasets of the upper jaw during orthodontic tooth movement}

Analysis of DCE-MRI datasets revealed an increased signal (area under the curve [AUC]) during OTM (Fig. 2d and 3c) compared to the contralateral control side, reflecting the degree of signal enhancement of the contrast agent in the tissue after molecular marker administration. Time to peak (TTP) was reduced at the OTM jaw side (Fig. 3d). In addition, we determined the washout rate and observed that the washout of the gadolinium-based contrast agent was accelerated during OTM (Fig. 3e).

\section{Discussion}

The aim of this pilot study was to establish an imaging methodology that allows noninvasive assessment of VEGFR-2 expression using MRI. This study was based on the idea that reduced local perfusion and concomitantly created hypoxic conditions during OTM result in increased VEGF-mediated angiogenesis. As current evidence supporting this assumption is scarce and actual perfusion and angiogenesis levels have not been evaluated before using advanced MRI imaging, we used a molecular MRI marker for VEGFR-2 coupled to gadolinium biotin to help shed light on this question. Here, we describe an imaging protocol that clearly visualizes uptake of the VEGFR-2-specific contrast agent after OTM including quantitative measures for noninvasive determination of VEGFR-2 expression.

In MRI analysis, T1-weighted images represent the standard sequences used to display variations in $\mathrm{T} 1$ relaxation times of various tissues in mice and humans. They are primarily dependent on the longitudinal relaxation of the net magnetization vector in a certain tissue [1]. In gen- 
eral, a radiofrequency pulse impacts on the alignment of spins, which are commonly orientated in a magnetic field, by transversing the orientation of the nuclear spins [1]. Accordingly, they return into the original alignment after a certain amount of time, which critically depends on the investigated tissue, as various tissues differ from each other in the duration needed to return to the initial orientation [1].

In our study, we observed an increased volume enhancement in T1-weighted imaging distally of the orthodontically moved first upper molar after injection of the VEGFR-2 marker. In future studies, this may be used to confirm an increased local expression of this receptor hinting at increased VEGF-induced angiogenesis taking place at tension areas of the periodontal ligament, which has been assumed before $[6,15,17,18]$.

The time for realignment of nuclear spins in an external magnetic field after a high-frequency pulse is defined as T1-relaxation time [1]. Thus, the duration strongly depends on multiple variables like composition of the tissue, magnetic flux density, and strength of the magnetic field. A reduced relaxation time, which was observed in our pilot study during OTM distal to the orthodontically moved first upper molar after injection of the VEGFR-2 marker, corresponds to an increased uptake of contrast agent.

In general, dynamic contrast-enhanced (DCE) MRI can determine the perfusion parameters of different tissues by calculation of T1-shortening evoked by a contrast agent, which diffuses through tissue (in this case the VEGFR-2 molecular marker), by evaluating $\mathrm{T} 1$ changes in tissues over a certain amount of time. One main characteristic of contrast agents, like the most commonly used gadolinium, is a rapid dissemination into the plasma, where it circulates through tissues via blood flow, as they can very easily pass through the vascular endothelium due to their small size. In DCE analysis, the time course of contrast agent enrichment is quantified, which strongly depends on the vasculariszation of the investigated tissue.

Despite the statements that can be taken from the presented pilot experiment, there are several limitations that should also be mentioned at this point. First, we only investigated one animal in this study as proof-of-principle and to reduce animal suffering. Thus, generalizability of our findings cannot be shown at the statistical level. Furthermore, no MRI control prior to insertion of the elastic bands could be recorded as a nonforce control to contrast our findings to. Given the fact that the procedure of MRI scanning is very time-consuming and the corresponding longterm anesthesia applied, MRI scanning prior to insertion may have affected the results, as the final MRI scan would have taken place only 4 days later due to the limited time of orthodontic tooth movement. Finally, we used an elastic band instead of a nickel-titanium (NiTi) coil to induce experimental tooth movement, as the appliance had to be in place during MRI measurements and NiTi coil springs would have created MRI artifacts. Therefore, we could not control the applied force during OTM. Additional examinations such as histological staining will be essential in the future to corroborate VEGFR-2 expression during orthodontic tooth movement in rats.

Nevertheless, we observed an increased AUC at the region of interest distally of the orthodontically moved first upper molar, whereas the time to peak and washout rate were all decreased compared to the untreated contralateral jaw side in our pilot study. These preliminary findings indicate that perfusion of this area was increased during OTM. According to current theory, blood perfusion is believed to be predominantly reduced at compression areas of the periodontal ligament with the tooth roots pressing against the alveolar bone surfaces of the alveolar sockets thus compressing the periodontal ligament (PDL) in-between [12, $13,15]$. A possible explanation for the observed increased blood perfusion in tension areas of the PDL could be the fact that VEGF-mediated angiogenesis has taken place within the OTM phase of four days, thus increasing the number of periodontal blood vessels, which has been postulated before $[6,12,13,15,17]$.

\section{Conclusions}

Our results from this pilot study, which for the first time used a VEGFR-2 (vascular endothelial growth factor receptor 2)-specific MRI (magnetic resonance imaging) contrast agent to assess tissue effects during OTM (orthodontic tooth movement), indicate that noninvasive MRI assessment of VEGFR-2 expression within the jaw and PDL (periodontal ligament) after OTM is feasible. Our preliminary results suggest that local perfusion is actually increased in tension areas of the PDL during OTM. This is most likely due to increased VEGF-mediated angiogenesis within the periodontal ligament at tension areas. Taken together, our pilot study provides a novel method and quantitative imaging markers to noninvasively assess VEGFR-2 expression during OTM.

Funding This study was funded by the German Orthodontic Society (DGKFO), grant Hofmann 03/2017.

Funding Open Access funding enabled and organized by Projekt DEAL.

\section{Declarations}

Conflict of interest A. Schröder, L. Seyler, E. Hofmann, L. Gölz, J. Jantsch, P. Proff, T. Bäuerle and C. Kirschneck declare that they have no competing interests. 
Ethical standards The experiment was carried out with the approval of the responsible authorities (Government of Lower Franconia, AZ: 55.2.2532-2-510) and in compliance with the German Animal Protection Act. In order to avoid unnecessary animal suffering, corresponding termination criteria were predefined and animal condition as well as gross body weight monitored daily.

Open Access This article is licensed under a Creative Commons Attribution 4.0 International License, which permits use, sharing, adaptation, distribution and reproduction in any medium or format, as long as you give appropriate credit to the original author(s) and the source, provide a link to the Creative Commons licence, and indicate if changes were made. The images or other third party material in this article are included in the article's Creative Commons licence, unless indicated otherwise in a credit line to the material. If material is not included in the article's Creative Commons licence and your intended use is not permitted by statutory regulation or exceeds the permitted use, you will need to obtain permission directly from the copyright holder. To view a copy of this licence, visit http://creativecommons.org/licenses/by/4. $0 \%$.

\section{References}

1. Murphy A, Jones J (2020) T1 weighted image. https://radiopaedia. org/articles/t1-weighted-image. Accessed 4 Apr 2020

2. Alhashimi N, Frithiof L, Brudvik P et al (2001) Orthodontic tooth movement and de novo synthesis of proinflammatory cytokines. Am J Orthod Dentofacial Orthop 119:307-312

3. Basdra EK (1997) Biological reactions to orthodontic tooth movement. J Orofac Orthop 58:2-15

4. Basdra EK, Komposch G (1997) Osteoblast-like properties of human periodontal ligament cells: an in vitro analysis. Eur J Orthod 19:615-621

5. Davidovitch Z, Montgomery PC, Gustafson GT et al (1976) Cellular localization of cyclic AMP in periodontal tissues during experimental tooth movement in cats. Calcif Tissue Res 19:317-329

6. Di Domenico M, D'apuzzo F, Feola A et al (2012) Cytokines and VEGF induction in orthodontic movement in animal models. J Biomed Biotechnol 2012:201689

7. Ferrara N (2004) Vascular endothelial growth factor: basic science and clinical progress. Endocr Rev 25:581-611

8. Greijer AE, van der Wall E (2004) The role of hypoxia inducible factor 1 (HIF-1) in hypoxia induced apoptosis. J Clin Pathol 57:1009-1014

9. He T, Smith N, Saunders D et al (2011) Molecular MRI assessment of vascular endothelial growth factor receptor- 2 in rat C6 gliomas. J Cell Mol Med 15:837-849

10. He T, Smith N, Saunders D et al (2013) Molecular MRI differentiation of VEGF receptor-2 levels in C6 and RG2 glioma models. Am J Nucl Med Mol Imaging 3:300-311

11. Kirschneck C, Proff P, Fanghänel J et al (2016) Reference genes for valid gene expression studies on rat dental, periodontal and alveolar bone tissue by means of RT-qPCR with a focus on orthodontic tooth movement and periodontitis. Ann Anat 204:93-105

12. Krishnan V, Davidovitch Z (2009) On a path to unfolding the biological mechanisms of orthodontic tooth movement. J Dent Res 88:597-608

13. Krishnan V, Davidovitch Z (2006) Cellular, molecular, and tissuelevel reactions to orthodontic force. Am J Orthod Dentofacial Orthop 129:469.e1-469.32
14. Marti HH, Risau W (1998) Systemic hypoxia changes the organspecific distribution of vascular endothelial growth factor and its receptors. Proc Natl Acad Sci U S A 95:15809-15814

15. Meikle MC (2006) The tissue, cellular, and molecular regulation of orthodontic tooth movement: 100 years after Carl Sandstedt. Eur J Orthod 28:221-240

16. Mohamed KM, Le A, Duong H et al (2004) Correlation between VEGF and HIF-1alpha expression in human oral squamous cell carcinoma. Exp Mol Pathol 76:143-152

17. Narimiya T, Wada S, Kanzaki H et al (2017) Orthodontic tensile strain induces angiogenesis via type IV collagen degradation by matrix metalloproteinase-12. J Periodontal Res 52:842-852

18. Niklas A, Proff P, Gosau M et al (2013) The role of hypoxia in orthodontic tooth movement. Int J Dent 2013:841840

19. Odagaki N, Ishihara Y, Wang Z et al (2018) Role of osteocytePDL crosstalk in tooth movement via SOST/sclerostin. J Dent Res 97(12):1374-1382. https://doi.org/10.1177/0022034518771331

20. Proff P, Römer P (2009) The molecular mechanism behind bone remodelling: a review. Clin Oral Investig 13:355-362

21. Römer P, Köstler J, Koretsi V et al (2013) Endotoxins potentiate COX-2 and RANKL expression in compressed PDL cells. Clin Oral Investig 17:2041-2048

22. Schröder A, Küchler EC, Omori M et al (2019) Effects of ethanol on human periodontal ligament fibroblasts subjected to static compressive force. Alcohol 77:59-70

23. Shoji-Matsunaga A, Ono T, Hayashi M et al (2017) Osteocyte regulation of orthodontic force-mediated tooth movement via RANKL expression. Sci Rep 7(1):8753. https://doi.org/10.1038/s41598017-09326-7

24. Shweiki D, Itin A, Soffer D et al (1992) Vascular endothelial growth factor induced by hypoxia may mediate hypoxia-initiated angiogenesis. Nature 359:843-845

25. Towner RA, Smith N, Doblas S et al (2008) In vivo detection of c-Met expression in a rat C6 glioma model. J Cell Mol Med 12:174-186

26. Towner RA, Smith N, Tesiram YA et al (2007) In vivo detection of c-MET expression in a rat hepatocarcinogenesis model using molecularly targeted magnetic resonance imaging. Mol Imaging 6:18-29

27. Waldo C, Rothblatt J (1954) Histologic response to tooth movement in the laboratory rat; procedure and preliminary observations. J Dent Res 33:481-486

28. Weissleder R, Mahmood U (2001) Molecular imaging. Radiology 219:316-333

29. Wolf M, Lossdörfer S, Marciniak J et al (2016) CD8+ T cells mediate the regenerative PTH effect in hPDL cells via Wnt10b signaling. Innate Immun 22:674-681

30. Wolf M, Lossdörfer S, Römer P et al (2016) Short-term heat pretreatment modulates the release of HMGB1 and pro-inflammatory cytokines in hPDL cells following mechanical loading and affects monocyte behavior. Clin Oral Investig 20:923-931

31. Yamaguchi M (2009) RANK/RANKL/OPG during orthodontic tooth movement. Orthod Craniofac Res 12:113-119

32. Ylä-Herttuala S, Rissanen TT, Vajanto I et al (2007) Vascular endothelial growth factors: biology and current status of clinical applications in cardiovascular medicine. J Am Coll Cardiol 49:1015-1026

Publisher's Note Springer Nature remains neutral with regard to jurisdictional claims in published maps and institutional affiliations. 